\title{
The prevalence of occult leiomyosarcoma at surgery for presumed uterine fibroids: a meta-analysis
}

\author{
Elizabeth A. Pritts ${ }^{1}$ - David J. Vanness ${ }^{2} \cdot$ Jonathan S. Berek $^{3} \cdot$ William Parker ${ }^{4}$. \\ Ronald Feinberg $^{5} \cdot$ Jacqueline Feinberg $^{5} \cdot$ David L. Olive $^{1}$
}

Received: 14 February 2015 / Accepted: 22 April 2015 /Published online: 19 May 2015

(C) The Author(s) 2015. This article is published with open access at Springerlink.com

\begin{abstract}
There is a concern regarding the risk of occult leiomyosarcomas found at surgery for presumed benign fibroids. We sought to produce a comprehensive review of published data addressing this issue and provide high-quality prevalence estimates for clinical practice and future research. A comprehensive literature search using the PubMed/ MEDLINE database and the Cochrane Library was performed. Inclusion criteria were human studies, peer-reviewed, with original data, involving cases for surgery in which fibroid-related indications were the primary reason for surgery, and histopathology was provided. Candidate studies (4864) were found; 3844 were excluded after review of the abstract. The remaining 1020 manuscripts were reviewed in their entirety, and 133 were included in the Bayesian binomial random effect meta-analysis. The estimated rate of leiomyosarcoma was 0.51 per 1000 procedures $(95 \%$ credible
\end{abstract}

This information was presented at the Obstetrics and Gynecology Devices Panel of the Medical Devices Advisory Committee; FDA, July 10-11, 2014, Washington, D.C., and ESGE 23rd Annual Congress; September 24-27, 2014, Brussels, Belgium, and the 43rd AAGL Global Conference; November 17-21, Vancouver, B.C., Canada.

Electronic supplementary material The online version of this article (doi:10.1007/s10397-015-0894-4) contains supplementary material, which is available to authorized users.

Elizabeth A. Pritts

epritts@wisconsinfertilty.com

1 Wisconsin Fertility Institute, Middleton, WI, USA

2 University of Wisconsin School of Medicine and Public Health, Madison, WI, USA

3 Stanford University School of Medicine, Stanford, CA, USA

4 University of California, Los Angeles, Los Angeles, CA, USA

5 Reproductive Associates of Delaware, Newark, DE, USA interval (CrI) $0.16-0.98$ ) or approximately 1 in 2000 . Restricting the meta-analysis to the 64 prospective studies resulted in a substantially lower estimate of 0.12 leiomyosarcomas per 1000 procedures $(95 \% \mathrm{CrI}<0.01-$ 0.75 ) or approximately 1 leiomyosarcoma per 8300 surgeries. Results suggest that the prevalence of occult leiomyosarcomas at surgery for presumed uterine fibroids is much less frequent than previously estimated. This rate should be incorporated into both clinical practice and future research.

Keywords Leiomyosarcoma $\cdot$ Fibroids $\cdot$ Surgery $\cdot$ Incidental malignancy $\cdot$ Prevalence

\section{Introduction}

Uterine fibroids, also known as leiomyomas or myomas, are a significant gynecologic problem, affecting $70-80 \%$ of all women during their reproductive years. These tumors are often symptomatic, producing complaints of abnormal bleeding, pain, and infertility in many of those afflicted. The disease represents a large economic burden for the health care system and significantly affects the quality of life of many with these tumors [1].

Two primary procedures have been utilized over the last century to treat myomas: the hysterectomy, for those who do not wish to retain their uterus, and myomectomy for those who wish to maintain uterine structure and function, often for future reproduction. Traditionally, these procedures were performed via a large abdominal incision (laparotomy), often required by the large size of the fibroid uterus.

Less invasive surgical approaches have been advocated and performed for many years, although with much less frequency than laparotomy. The challenge for surgeons performing these less invasive operations is the usual 
requirement to remove large amounts of tissue through small apertures.

Manual morcellation via scalpel or other devices has been available for decades, allowing the completion of hysterectomies (and even myomectomies) involving quite large specimens through a vaginal or mini-laparotomy route. The advent of minimally invasive surgery (MIS) utilizing endoscopy initially provided a resurgence in morcellation. As MIS skills improved among surgeons and as equipment improved in concert with the enhanced surgical skills being developed, endoscopic procedures for both hysterectomy and myomectomy increased in number and popularity. A key innovation allowing the performance of these procedures endoscopically was the development and utilization of the electromechanical (or "power") morcellator.

The US Food and Drug Administration (FDA) first approved an electromechanical morcellation device in 1995, and a number now exist in the market. However, recently, the FDA issued a statement discouraging the use of such devices, citing safety concerns, chief among these being the inadvertent dissemination of occult uterine cancer in patients undergoing hysterectomy and myomectomy for presumed benign leiomyomata [2]. Their stated prevalence for unsuspected uterine sarcoma, based upon their review of the medical literature, was 1 in 352 for any sarcoma and 1 in 498 for leiomyosarcoma.

We and others were concerned that the FDA figures might not be the product of a comprehensive and systematic review. In response, our group decided to further investigate the prevalence of uterine leiomyosarcoma among women undergoing surgery for presumed fibroids with a thorough review of published studies of myomectomy or hysterectomy performed for the indication of symptomatic fibroids that included histopathologic analysis of all tissue removed.

\section{Sources}

A literature search was initially performed using the PubMed/MEDLINE database and the Cochrane Library. The search was performed for all manuscripts published after 1960 and all languages using the search terms "myoma," "leiomyoma," "fibroid," "hysterectomy," "incidental malignancy," "myomectomy," "neoplasm," "leiomy os arcoma," "incidence," "pathology," "histopathology," "morcellation," and "complication." These terms were used alone and in combination. All references found were evaluated for the inclusion and exclusion criteria listed below and their bibliographies handsearched for other potentially relevant publications. One author (EAP) conducted a preliminary review; all papers deemed to meet inclusion and exclusion criteria were then reviewed by at least one other author for categorization (RF, JF, DLO). If a disagreement was found between reviewers, a conference involving multiple reviewers was used to reach a decision.

\section{Study selection}

Inclusion criteria encompassed publications involving humans that were peer-reviewed. All publications were required to contain original data. Papers were included if they involved cases for surgery (hysterectomy or myomectomy) in which fibroid-related indications were the primary reason for surgery. If this was the exclusive focus of the manuscript, then all cases in the publication were extracted. If, however, there were multiple indications for surgery, only those cases with a fibroid-related primary indication were extracted and included in the analysis. To avoid case reports, a minimum of five subjects from an individual study was necessary for inclusion in this review.

Only those manuscripts in which the postoperative histopathologic findings were provided for all extracted patients were included in the analysis. Manuscripts stating "all specimens were sent to pathology" without final reports were deemed inadequate for inclusion. If the histopathologic description of a leiomyosarcoma in any study was inconsistent with the current World Health Organization (WHO) diagnostic criteria, we noted this, but included it as a leiomyosarcoma in our evaluable data [3] (see below).

Studies that initially searched their databases for a pathologic diagnosis of fibroids, then worked backward to uncover the primary indications for surgery, were excluded. Similarly, all prospective analyses that a priori excluded any patient with malignancy were excluded from the review. All letters to the editor, abstracts, and all other non-peer-reviewed publications of data were omitted. In many cases, we found multiple reports based on a single patient cohort or overlapping cohorts. When this was encountered, we included only one of these papers, with selection based on the following hierarchy of priorities: the publication with the most comprehensive presentation of information with the most leiomyosarcomas, the largest number of patients, or the one that was the most recent. Studies in which "sarcomas" or "malignancies" were found but were not specified as "leiomyosarcoma" were excluded. The first study adequate for inclusion was published in July, 1984; the final was published in September, 2014.

After a thorough search of the literature, 4864 candidate studies were found. Of these, 3844 were excluded after review of the abstract. The remaining 1020 manuscripts were reviewed in their entirety. Of these, 887 were excluded after not meeting the inclusion and exclusion criteria above. One hundred thirty-three publications with 134 analyses (1 publication included both retrospective and prospective data) comprised our evidence base and were used in the final analysis as they contained postoperative histopathologic information for 
all reported patients (Fig. 1) (Supplemental Digital Content 1: Tables of all included studies and their characteristics).

\section{Statistical methods}

We conducted our meta-analysis using a Bayesian binomial random effect specification (R 3.1.1; JAGS 3.3; Supplemental Digital Content 2: Bayesian statistical details and model code). We estimated separate models for prospective and retrospective studies and a model combining both study types. Inference was performed directly on posterior samples generated by Markov chain Monte Carlo. We calculated the rate of leiomyosarcoma per 1000 cases using the posterior random effect mean and constructed $95 \%$ credible intervals (CrIs) using the posterior 2.5 and 97.5 percentiles and on the probability scale by applying the logistic retransformation to the posterior mean of the random effect mean parameter. We assessed heterogeneity on the log-odds scale by calculating the posterior mean of the random effect variance parameter $\tau^{2}$ and on the probability scale by applying the logistic transformation to the posterior mean of the random effect mean parameter $\mu_{\alpha} \pm 1.96 \tau$.

For comparison with the FDA analysis, we used an unadjusted binomial mixed model with exact $95 \%$ confidence intervals (CIs) (PROC GLIMMIX SAS 9.4).

Sensitivity analysis was conducted to determine whether the conclusions were robust in the presence of small numerical changes in events (leiomyosarcomas).

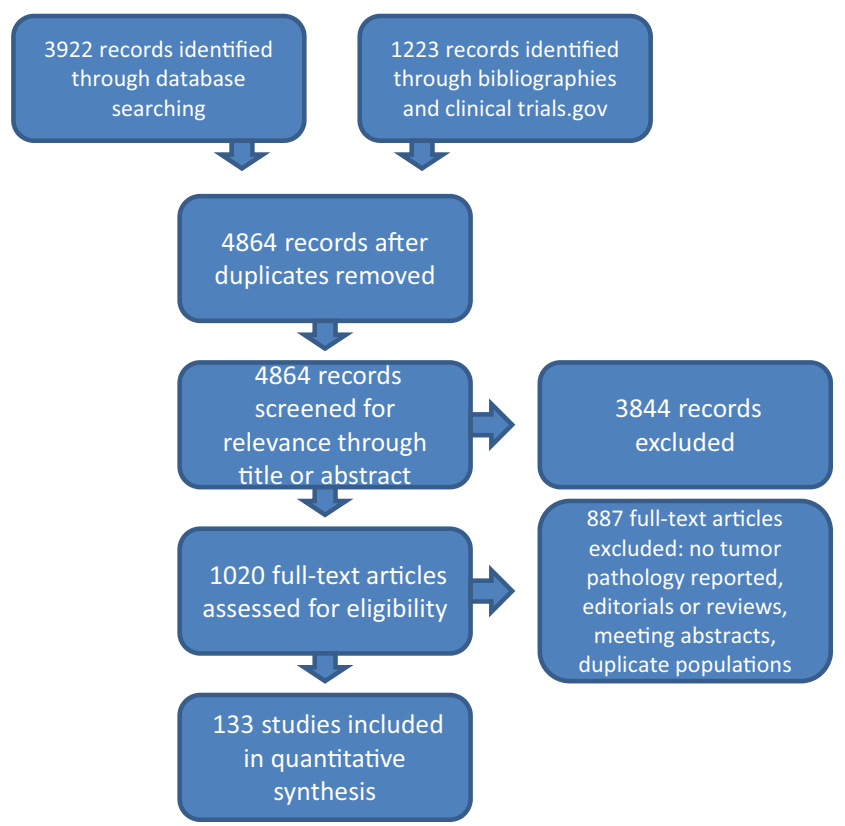

Fig. 1 PRISMA evaluation of studies

\section{Results}

a. Rate of occult leiomyosarcoma in surgery for presumed fibroids

Sixty-four published prospective analyses were included in this review: 38 as prospective cohorts [4-41] and 26 as part of a randomized clinical trial [42-67]. Thirteen studies contained more than 100 subjects, 34 included 25-99 subjects, and six had less than 25 subjects. Thirty-five studies were limited to myomectomies, 24 involved only hysterectomies, four studies included patients having either, and one did not state the type of surgery (Table 1). These analyses encompassed 5223 women, with three leiomyosarcomas being found. Only two prospective analyses found a leiomyosarcoma [34, 36].

Seventy published analyses with retrospective cohorts qualified for this review, encompassing a total of 24,970 patients [33, 68-136]. Forty-four cohorts contained more than 100 women, 19 had 25-99 subjects, and seven included less than 25 women. Twenty-five reports were limited to myomectomies, 33 involved only hysterectomies, and 12 included women undergoing either (Table 1). Of these, 29 were noted to have leiomyosarcomas postsurgically. The leiomyosarcomas were found in 13 of the 70 retrospective analyses $[75,79,84,98,100,101,106,114,115,124,125$, $128,129]$.

Taken together, these 134 analyses reported 32 leiomyosarcomas in 30,193 women undergoing surgery (Supplemental Digital Content 3: Tables of all leiomyosarcomas, sources, and their histopathology). A forest plot of these studies can be seen in Fig. 2. The meta-analysis of the 64 prospective analyses provided an estimated prevalence of leiomyosarcoma to be 0.12 per 1000 surgeries $(95 \%$ credible interval $<0.01-0.75$ ) or approximately 1 leiomyosarcoma per 8300 surgeries. When restricted to the 70 retrospective analyses, the estimated prevalence was 0.57 per 1000 surgeries $(95 \% \mathrm{CrI}$

Table 1 The studies: number of patients and type of surgery

\begin{tabular}{llll}
\hline & $\begin{array}{l}\text { Randomized } \\
\text { controlled studies }\end{array}$ & $\begin{array}{l}\text { Prospective } \\
\text { studies }\end{array}$ & $\begin{array}{l}\text { Restrospective } \\
\text { studies }\end{array}$ \\
\hline \# of patients & & & \\
$>100$ patients & 5 & 8 & 44 \\
25-99 patients & 15 & 19 & 19 \\
$<25$ patients & 6 & 11 & 7 \\
Type of surgery & & & \\
Myomectomy & 12 & 23 & 25 \\
Hysterectomy & 13 & 11 & 33 \\
Both & 1 & 3 & 12 \\
Unknown & & 1 & \\
\hline
\end{tabular}




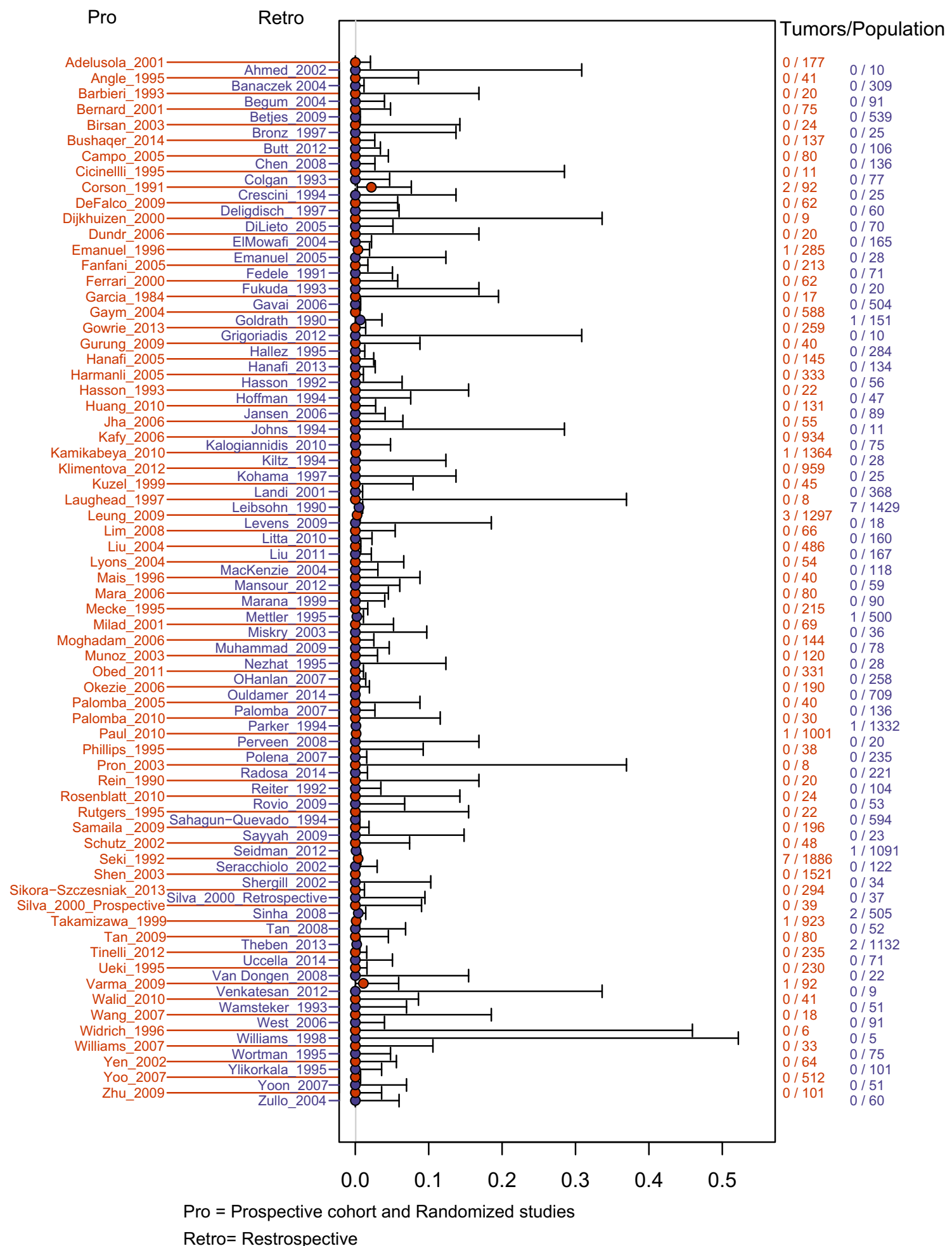

Fig. 2 Forest plot of included studies. Pro prospective cohort and randomized studies, Retro retrospective

$0.17-1.13$ ) or approximately 1 leiomyosarcoma per 1700 surgeries. Meta-analysis of all 134 analyses estimated prevalence to be 0.51 per 1000 surgeries $(95 \% \mathrm{CrI}$
0.16-0.98) or approximately 1 leiomyosarcoma for every 2000 procedures (Table 2). The posterior mean of the random effect variance parameter $\tau^{2}=1.375$, which 
Table 2 Meta-analyses of evidence base Bayesian model generalized linear mixed model

\begin{tabular}{llllll}
\hline Dataset & $\begin{array}{l}\text { Number of } \\
\text { studies }\end{array}$ & $\begin{array}{l}\text { Posterior mean; } \\
\text { rate per 1000 surgeries }\end{array}$ & $\begin{array}{l}95 \% \text { credible } \\
\text { interval }\end{array}$ & $\begin{array}{l}\text { Rate per 1000 } \\
\text { surgeries }\end{array}$ \\
\hline All studies & 133 & 0.51 & $0.16,0.98$ & 0.79 & $\begin{array}{l}95 \text { confidence } \\
\text { interval }\end{array}$ \\
Prospective studies & 64 & 0.12 & $0,0.75$ & 0.48 & $0.5,1.26$ \\
Retrospective studies & 70 & 0.57 & $0.17,1.13$ & 0.87 & $0.14,1.72$ \\
All studies, $N \geq 100$ & 57 & 0.55 & $0.17,1.06$ & 0.81 & $0.52,1.46$ \\
Prospective studies, $N \geq 100$ & 13 & 0.06 & $0,0.62$ & 0.45 & $0.49,1.33$ \\
Retrospective studies, $N \geq 100$ & 44 & 0.59 & $0.18,1.15$ & 0.85 & $0.06,3.15$ \\
FDA dataset & 9 & 1.86 & $0.7,3.32$ & 2.02 & $0.5,1.45$ \\
\hline
\end{tabular}

implies that there is $95 \%$ probability that the 134 underlying true study-specific rates of LMS ranged between 0.09 and 4.50 per 1000 surgeries.

\section{b. Sensitivity analysis}

Sensitivity of our analysis was tested in a variety of ways. First, seven leiomyosarcomas from three retrospective analyses uncovered in our search failed to meet current diagnostic criteria. We correctly classified these seven tumors as non-malignant and reran our analysis; the resulting prevalence estimate from our complete evidence base was essentially unchanged from the previous estimate (Table 3).

Secondly, we tested the robustness of the estimates by adding one leiomyosarcoma to either the largest or smallest study reporting no such malignancies. This maneuver changed the estimated rate per 1000 surgeries by $0.02-0.08$ for the meta-analysis of all studies and by $0.01-0.24$ per 1000 cases for the meta-analysis of prospective datasets only (Table 3).
Finally, we investigated the responsiveness of our Bayesian methodology to heterogeneity of observed rates among studies by reallocating the 32 observed leiomyomas to studies in proportion to their sample size (two each to the six largest studies and one each to the next 20 largest). This maneuver minimizes heterogeneity in observed rates and therefore should yield an estimate that approaches the crude calculated rate (number of leiomyosarcomas/number of surgeries). This was in fact the case (Table 3).

\section{Discussion}

This meta-analysis of the existing literature reveals an estimated prevalence of leiomyosarcomas in surgeries for presumed fibroids that is substantially less than that previously estimated. For this reason, it is important to take a close look at how the estimates were derived and what they mean clinically.

Rigorously conducted systematic review and meta-analysis is widely recognized as among the highest standards of evidence for informed medical decision-making [137]. When

Table 3 Sensitivity analyses

\begin{tabular}{llc}
\hline Dataset & Posterior mean rate per 1000 & $95 \%$ credible interval \\
\hline All studies & 0.51 & $0.16,0.98$ \\
All studies; add 1 LMS case to largest study & 0.59 & $0.21,1.08$ \\
All studies; add 1 LMS case to smallest study & 0.53 & $0.16,1.02$ \\
All studies; reclassification based on histopathology & 0.53 & $0.16,0.99$ \\
Prospective studies & 0.12 & $0,0.75$ \\
Prospective studies; add 1 LMS case to largest study & 0.36 & $0,1.27$ \\
Prospective studies; add 1 LMS case to smallest study & 0.13 & $0,0.89$ \\
All studies; crude test rate & 1.03 & $0.69,1.43$ \\
All studies; actual crude rate & 1.06 & $0.75,1.50$ \\
\hline
\end{tabular}

\section{LMS leiomyosarcoma}

See text for explanation of adding LMS cases and reclassification.

Crude test rate involved adding 32 LMS to 31 largest studies

Actual crude rate is (number of LMS/number of total surgeries) for all studies 
assessing the rate of rare events, formal meta-analysis may offer the only reliable and accessible approach. It is often asked why crude rates calculated by summing the total number of events (in this case leiomyosarcomas) across studies and dividing by the total number of observations (surgeries) is not adequate for estimating the prevalence. The answer lies in the fact that the aggregate of populations from multiple studies is not the same as a single large population undergoing sampling. The heterogeneity among studies for inclusion and exclusion, confounders, and even definitions of risk factors and outcomes leads to tremendous bias in calculating a crude prevalence $[138,139]$. In statistical terms, crude calculations are only appropriate if [1] each study was an independent and identically distributed measure of the overall population, and [2] the variance of each study's estimate is known [140]. These conditions are rarely if ever met.

Heterogeneity among studies in a meta-analysis also dictates the type of analytic approach. When included studies investigate the same population with the same research questions and structure, a fixed effect model can be used. As the vast majority of studies in this analysis were not designed to estimate the prevalence of leiomyosarcomas in surgery for presumed fibroids, some degree of statistical heterogeneity is likely. Thus, a random effect meta-analysis, which assumes that design differences lead each study to produce rates that are different but related to the rate of the population of interest, was the approach used here [141]. The estimated random effect variance parameter $\tau^{2}=1.375$ suggests substantial heterogeneity between studies. However, a high degree of statistical variability between studies is to be expected in rare events random effect meta-analysis given the large number of studies with zero events (thus having arbitrarily negative log-odds).

Finally, there are a number of random effect models from which to choose. Our choice was to use a Bayesian binomial model, which has a number of advantages over classical meta-analysis techniques that are particularly important given the complexities of estimating rare event rates [141, 142] (for details, see supplemental digital content 2). Bayesian random effect meta-analysis has been used extensively under such conditions for clinical decision-making and policy analysis [143].

The best available estimate for the rate of occult leiomyosarcoma lies in the data collected prospectively: that gathered from randomized trials and prospective cohort studies. In these investigations, the data collection is begun at a predefined time point, consecutive cases are included avoiding selection bias and patient exclusion, and the data are uniformly collected for all surgeries throughout the duration of the study. In this review, the estimated prevalence of leiomyosarcoma using only data derived from prospective studies was 0.12 per 1000 surgeries, with a $97.5 \%$ probability of being less than 0.75 per 1000 surgeries. Our sensitivity analysis suggests that this estimate is modestly sensitive to adding an incremental case of leiomyosarcoma to the largest study reporting zero events, as would be expected given the small number of prospective studies finding leiomyosarcomas.

Expanding the evidence to include retrospective studies yields an estimated rate of 0.51 per 1000 surgeries, with $97.5 \%$ probability of being less than 0.98 per 1000 . Retrospective data collection and analysis has a number of inherent biases, and these can affect the calculated prevalence in either direction. Data that cannot be found when doing chart reviews may not be representative of the entire study population but rather may represent an enriched sample. Prevalence would be underestimated if, for example, records of leiomyosarcomas were more frequently undiscovered because of being moved to hospital risk management files! Conversely, retrospective studies are often initiated after the discovery of an index case at an institution. If the ensuing study population then includes the index case, the resulting bias will uniformly overestimate rate of prevalence. In the case of leiomyosarcomas in fibroid surgery, this definitely occurred in at least two published studies $[79,100]$. It is reasonable to suspect that other retrospective studies were also initiated in response to an index case but did not report this reason.

Our prevalence estimates differ substantially from that calculated in the FDA meta-analysis, which was 2.02 per 1000 surgeries. Our group has been asked why these differences are so profound. They can be attributed to both the base of evidence and the statistical methodology. To sort out the relative contribution of each, we applied our Bayesian methods to the FDA dataset and estimated a rate of 1.86 per 1000 surgeries (95\% CrI 0.70-3.32), which is about $8 \%$ lower than the FDA's rate (Table 2). Thus, while differences in methodology accounted for some of the difference in estimated rates, differences in the evidence base accounted for a much larger share.

The evidence base used in this study differed from the studies utilized by the FDA in a number of significant ways. First, our search and screen protocol identified all papers where surgery was being performed for presumed fibroids and where histopathology results were explicitly provided for every subject in the study. This strategy yielded 134 analyses in 133 published studies.

In contrast, to obtain their evidence, the FDA performed a targeted search using the search terms "uterine cancer" AND "hysterectomy or myomectomy" AND "incidental cancer or uterine prolapse, pelvic pain, uterine bleeding, and uterine fibroids." Using uterine cancer as a required search term necessitates the presence of uterine cancer in the manuscripts available for analysis, while those studies without uterine cancers would be overlooked. Indeed, this was the case: $8 / 9$ studies found in their search contained at least one leiomyosarcoma. Of the 133 published studies included in our review, 118 had no leiomyosarcomas and thus would not have appeared in the FDA's targeted search. 
A second difference lies in the fact that only studies with more than 100 subjects were included in the evidence base compiled by the FDA; their reasoning was that this would reduce bias from smaller studies. Recognizing the arbitrary nature of any predefined size threshold, our preferred approach was to include eligible studies of all sizes, while allowing for the Bayesian model to weigh each study according to its size and degree of statistical heterogeneity.

Nevertheless, the number of studies included in our evidence base with 100 or more observations was 57, a number far greater than that of the FDA. Restricting our meta-analysis approach to just these 57 prospective and retrospective studies resulted in a prevalence estimate essentially unchanged from our analysis of all 134 studies and approximately one-fourth that of the FDA's estimates: 0.55 per 1000 (95\% CrI 0.17 to 1.06) (see Table 2). Applying the sample size restriction to our prospective-only dataset resulted in inclusion of 13 studies and an estimated rate of 0.06 per $1000(95 \% \mathrm{CrI}<0.01$ to 0.62 ). Thus, even utilizing the same arbitrary study size restriction as the FDA, our more comprehensive database significantly lowers the prevalence estimate from their original report.

Third, the FDA included only studies that exclusively examined procedures performed for presumed leiomyomas; if multiple indications were listed by the author of the study, it was excluded from their evidence base and was unavailable for analysis. However, many publications containing multiple indications for surgery contained unequivocal information about those women with a primary surgical indication of fibroids and the data were easily extractable. They were included in our evidence base if the patients undergoing hysterectomy or myomectomy for fibroids were clearly identified, if histopathology was performed on all cases, and if results were explicitly provided.

Fourth, the FDA excluded all non-English articles from consideration. We felt the inclusion of non-English publications made for a more comprehensive review of the subject and thus included studies regardless of the language of publication.

Fifth, the FDA included one non-peer-reviewed abstract [144] and one letter to the editor [145] in their dataset. We excluded these and other similar data, restricting our analysis to peer-reviewed publications containing five or more applicable subjects. Parenthetically, the letter to the editor included in the FDA evidence base was written in English [145]. The original data were reported in their entirety in a French language publication. We excluded the letter to the editor but found the original, peer-reviewed publication and included it in our evidence base. There were three leiomyosarcomas presented in this study [101].

Finally, we note that in the FDA's review of the nine studies referenced, eight were retrospective studies $[98,100,101$, $106,114,124,128,144]$ and one was a report from prospectively collected data [34]. Such a preponderance of retrospective reports raises concerns of significant ascertainment bias in the resulting prevalence rate. Our analysis contained a sufficient number of prospective studies to allow analysis restricted to only these, producing what we believe to be the most appropriate evidence base from which to calculate prevalence.

An additional bias may affect the analysis in both our study and that of the FDA. Many of the publications used were from referral centers, where patients are often sent for surgery because of an increased suspicion of additional pathology; without the ability to exclude such cases from the routine hysterectomy or myomectomy for presumed fibroids, the rate of sarcoma will be overstated. This could be compounded by the known bias of non-publication of negative results. A group looking for occult sarcomas with zero events in their study would be less likely to submit for or be accepted for publication.

Despite the comprehensiveness of this review, there are still potential shortcomings of this type of assessment. First, due to the large number of publications involving surgery for uterine fibroids from around the world, it is possible that some went undiscovered by our investigation. However, the large number of studies evaluated and the breadth of contexts considered suggest that such publications are few in number. Another related concern would be that if only a few leiomyosarcomas were overlooked, the calculated prevalence might change substantially. This is unlikely, however, due to the relatively small changes in prevalence seen with our sensitivity analysis.

It is also possible that leiomyosarcomas were missed in the surgeries performed due to incomplete removal of all fibroids or inadequate histopathologic examination. While we do not have evidence to estimate this rate, we believe this to be at most a relatively rare phenomenon. Nevertheless, our sensitivity analyses suggested robustness of our results, as there were relatively small changes in estimated rates from the addition of an incremental case of leiomyosarcoma to one large or small trial previously reporting no cases. There was also a relatively small change when correctly categorizing seven benign tumors that were originally diagnosed as leiomyosarcomas.

Concern might also be expressed that the vast majority of studies included in this analysis, including all prospective studies and randomized controlled trials, were not designed to address the issue of leiomyosarcoma prevalence in such surgeries. Thus, inclusion criteria may have inadvertently eliminated many subjects who would be at higher risk for such malignancies. While this is undoubtedly the case with some trials, the large number of studies and the widely varying reasons for study performance speak against a systematic bias. Age ranges were similar for all datasets and very few restricted patient inclusion a priori to premenopausal women (Table 4). Moreover, the wide-ranging study hypotheses suggest that the 
Table 4 Age distributions by study type and histopathology

\begin{tabular}{llccc}
\hline Dataset & Study number & Premenopausal only & Study mean ages & Age range \\
\hline Randomized trials & 26 & 10 & $35.8-53.4$ & $20-70$ \\
Prospective & 38 & 4 & $28.9-67.4$ & $20-83$ \\
Retrospective & 70 & 0 & $32.6-59.6$ & $19-91$ \\
Studies with leiomyosarcomas & 14 & 0 & $32.6-48.0$ & $21-81$ \\
Leiomyosarcoma patients & - & - & & $30-63$ \\
& & & & $17 \leq 50$ \\
& & & & $6>50$ \\
& & & 9 unknown
\end{tabular}

information obtained is applicable to real-world clinical situations where surgery is performed for uterine fibroids.

We note that during data extraction, studies were excluded from our analysis when they stated that all specimens were sent for histopathologic analysis, but the results were not included in the publications. In these cases, we expect that the tumors were benign, as surely an event such as an occult leiomyosarcoma would warrant reporting. Excluding such studies potentially underestimated benign cases in our study, but we believe that our conservative approach and rigorous inclusion criteria increase the credibility of our prevalence rate.

A final issue worth noting is that of the criteria for the diagnosis of leiomyosarcoma. The criteria used today for leiomyosarcoma are those adopted by the World Health Organization in 2003 [3]. These criteria indicate that a malignant neoplasm composed of cells demonstrating uterine smooth muscle differentiation with coagulative tumor cell necrosis (not hyaline necrosis) is a leiomyosarcoma. If no such necrosis exists, then the diagnosis is made only if the mitotic index is $\geq 10$ mitoses per 10 high-power fields and there is diffuse, moderate to severe cytologic atypia. The microscopic criteria to meet each of the three requirements are quite specific.

Many of the leiomyosarcomas found in our search provided histologic detail in the manuscript. Interestingly, 7 of the 32 "leiomyosarcomas" found in our search would, based on current WHO criteria, not be so classified today (Table 5). Further validation of their non-malignant nature is found in the fact that none of the seven had recurrence following surgery. Despite convincing evidence that these seven tumors were not in fact leiomyosarcomas, we have maintained the original diagnosis in our calculations. Our sensitivity analysis suggests these mislabeled tumors had little impact on the estimated prevalence. Nevertheless, this factor highlights a potential bias in utilizing data from older or less highly scrutinized studies: the potential for overestimating prevalence of clinically relevant leiomyosarcomas via misinterpretation of histopathology. Our search for this review included manuscripts published after 1960 , in an attempt to be as all-inclusive as possible. We found no studies that met inclusion criteria between 1960 and 1983. The FDA's inclusion dates for studies were between 1980 and 2014, making comparison of these two analyses justifiable. However, both reviews are likely to be overstating the number of actual leiomyosarcomas uncovered.

While we have found that the prevalence of occult leiomyosarcoma is less than previously estimated, this does not negate the fact that such occult malignancies can and do occur. Furthermore, a number of other malignancies have been found at these surgical procedures. It is ideal to diagnose a tumor accurately prior to deciding the type of surgery that is appropriate. The more common

Table 5 Tumors inconsistent with World Health Organization 2003 leiomyosarcoma criteria

\begin{tabular}{lllll}
\hline Author/date type & Leiomyoma sub-type & Age (years) & Pathology & Recurrence \\
\hline œLeibsohn/1990 retro & Atypical & 36 & 6 mitoses/10 HPF, "poorly demarcated," cellular atypia & NED 6 months \\
& Atypical & 48 & 7 mitoses/10 HPF, cellular atypia & NED 16 months \\
œParker/1994 retro & Atypical & 30 & Irregular infiltrative borders, mild nuclear atypia, 5-8 mitoses/10 HPF & NED “years” \\
Seki/1992 retro & Mitotically active & 33 & 6 mitoses/10 HPF, no cellular atypia & NED 11 months \\
& Mitotically active & 34 & 5 mitoses/10 HPF, no cellular atypia & NED 57 months \\
& Mitotically active & 43 & 8 mitoses/10 HPF, no cellular atypia & NED 61 months \\
& Mitotically active & 43 & 9 mitoses/10 HPF, no cellular atypia & NED 72 months \\
\hline
\end{tabular}

$H P F$ high-powered field

Retro retrospective

$\infty$ included in FDA analysis

$N E D$ no evidence of disease 
types of uterine cancers may be diagnosed preoperatively, but there is no accurate way to do so for leiomyosarcomas. Many uterine leiomyosarcomas, particularly in younger women, are diagnosed after the tumor has been removed surgically. It was beyond the scope of this analysis to detail or quantify the risk of other cancers in surgery for presumed fibroids, but investigation should continue for a more thorough elucidation of the risks of all such tumors as well as the relative benefits of different surgical approaches. We believe that such data will allow more meaningful research into the decision analysis required for this complex clinical issue.

Acknowledgments The authors express their profound gratitude to Robert Koehler, Chief Librarian, and Meghan Kasprzyk, Library Assistant, Meriter-Unity Point Health Medical Library, Madison, WI.

Authors contributions EA Pritts: protocol/project development, data collection and evaluation, data analysis, and manuscript writing/editing.

DJ Vanness: data analysis and manuscript writing/editing.

JS Berek: data analysis and manuscript writing/editing.

W Parker: data analysis and manuscript writing/editing.

R Feinberg and J Feinberg: project development, data collection, and evaluation.

DL Olive: protocol development, data collection and evaluation, data analysis, and manuscript writing/editing.

Conflict of interest Elizabeth A. Pritts, David J. Vanness, Jonathon S. Berek, William Parker, Ronald Feinberg, Jacqueline Feinberg, and David L. Olive all declare that they have no conflict of interest.

On behalf of all authors, the corresponding author states that there is no conflict of interest.

Ethical statement All procedures performed in studies involving human participants were in accordance with the ethical standards of the institutional and/or national research committee and with the $1964 \mathrm{Hel}-$ sinki Declaration and its later amendments or comparable ethical standards. For this type of study, formal consent is not required. This article does not contain any studies with animals performed by any of the authors.

Open Access This article is distributed under the terms of the Creative Commons Attribution 4.0 International License (http:// creativecommons.org/licenses/by/4.0/), which permits unrestricted use, distribution, and reproduction in any medium, provided you give appropriate credit to the original author(s) and the source, provide a link to the Creative Commons license, and indicate if changes were made.

\section{References}

1. Rowe MK, Kanouse D, Mittman BS, Bernstein SJ (1999) Quality of life among women undergoing hysterectomies. Obstet Gynecol 93:915-921

2. Quantitative assessment of the prevalence of unsuspected uterine sarcoma in women undergoing treatment of uterine fibroidssummary and key findings. http://www.fda.gov/downloads/ AdvisoryCommittees/CommitteesMeetingMaterials/
MedicalDevices/MedicalDevices AdvisoryCommittee/ ObstetricianandGynecologyDevices/UCM404148.pdf. Referenced July 25, 2014

3. WHO Classification of tumors. In: Tavassoli FA, Devilee P, editors. Pathology and genetics of tumors of the breast and female genital organs. Lyon: IARC Press; 2003. p. 233-38

4. Ahmed AA, Stachurski J, Abdel Aziz E et al (2002) Minilaparotomy-assisted vaginal hysterectomy. Int J Gynecol Obstet 76:33-39

5. Begum S, Khan S (2004) Audit of leiomyoma uterus at Khyber teaching hospital Peshawar. J Ayub Med Coll Abbottabad 16(2): 46-49

6. Bernard JP, Rizk E, Camatte S et al (2001) Saline contrast sonohysterography in the preoperative assessment of benign intrauterine disorders. Ultrasound Obstet Gynecol 17:145-149

7. Birsan A, Deval B, Detchev R et al (2003) Vaginal and laparoscopic myomectomy for large posterior myomas: results of a pilot study. Eur J Obstet Gynecol Reprod Biol 110:89-93

8. Bronz L, Suter T, Rusca T (1997) The value of transvaginal sonography with and without saline instillation in the diagnosis of uterine pathology in pre-and postmenopausal women with abnormal bleeding or suspect sonographic findings. Ultrasound Obstet Gynecol 9:53-58

9. Campo S, Campo V, Gambadauro P (2005) Short-term and longterm results of resectoscopic myomectomy with and without pretreatment with GnRH analogs in premenopausal women. Acta Obstet Gynecol Scand 84:756-760

10. Chen S, Chang D, Sheu B et al (2008) Laparoscopic-assisted vaginal hysterectomy with in situ morcellation for large uteri. J Minim Invasive Gynecol 15:559-565

11. Cicinelli E, Romano F, Anastasio PS, Blasi N, Parisi C, Galantino P (1995) Transabdominal sonohysterography, transvaginal sonography, and hysteroscopy in the evaluation of submucous myomas. Obstet Gynecol 85:42-47

12. Crescini C, Amuso G, Cappato M et al (1994) Elettroresezione transcervicale dei miomi sottomucosi. Minerva Ginecol 46:395-402

13. Dijkhuizen F, De Vries LD, Mol B et al (2000) Comparison of transvaginal ultrasonography and saline infusion sonography for the detection of intracavitary abnormalities in premenopausal women. Ultrasound Obstet Gynecol 15:372-376

14. Fanfani F, Fagotti A, Bifulco G et al (2005) A prospective study of laparoscopy versus minilaparotomy in the treatment of uterine myomas. J Minim Invasive Gynecol 12:470-474

15. Fedele L, Bianchi S, Dorta M, Brioschi D, Zanotti F, Vercellini P (1991) Transvaginal ultrasonography versus hysteroscopy in the diagnosis of uterine submucous myomas. Obstet Gynecol 77:745-748

16. Garcia CR, Tureck RW (1984) Submucosal leiomyomas and infertility. Fertil Steril 42:16-19

17. Hoffman M, DeCesare S, Kalter C (1994) Abdominal hysterectomy versus transvaginal morcellation for the removal of enlarged uteri. Am J Obstet Gynecol 171:309-315

18. Jansen FW, de Kroon CD, van Dongen H, Grooters C, Louwe L, Trimbos-Kemper T (2006) Diagnostic hysteroscopy and saline infusion sonography: prediction of intrauterine polyps and myomas. J Minim Invasive Gynecol 13:320-324

19. Kalogiannidis I, Prapas N, Xiromeritis P et al (2010) Laparoscopically assisted myomectomy versus abdominal myomectomy in short-term outcomes: a prospective study. Arch Gynecol Obstet 281:865-870

20. Kiltz RJ, Rutgers J, Phillips J, Murugesapillai ML, Kletzky OA (1994) Absence of a dose-response effect of leuprolide acetate on leiomyomata uteri size. Fertil Steril 61(6):1021-1026

21. Kohama T, Hashimoto S, Ueno H, Terada S, Inoue M (1997) A technique of minilaparotomy-assisted vaginal hysterectomy. Obstet Gynecol 89:127-129 
22. Kuzel D, Toth D, Fucikova Z, Cibula D, Hruskova H, Zivny J (1999) Hysteroscopic resection of submucous myomas in abnormal uterine bleeding: results of a four-year prospective study. Ces Gynek 64:363-367

23. Landi S, Zaccoletti R, Ferrari L, Minelli L (2001) Laparoscopic myomectomy: technique, complications, and ultrasound scan evaluations. J Am Assoc Gynecol Laparosc 8(2):231-240

24. Laughead MK, Stones LM (1997) Clinical utility of saline solution infusion sonohysterography in a primary care obstetricgynecologic practice. Am J Obstet Gynecol 176:1313-1318

25. Liu L, Li Y, Xu H, Chen Y, Zhang G, Liang Z (2011) Laparoscopic transient uterine artery occlusion and myomectomy for symptomatic uterine myoma. Fertil Steril 95:254-258

26. Liu WC, Tzeng CR, Yi-Jen C, Wang PH (2004) Combining the uterine depletion procedure and myomectomy may be useful for treating symptomatic fibroids. Fertil Steril 82:205-210

27. Mara M, Fucikova Z, Kuzel D, Sosna O, Dundr P, Kriz P et al (2006) Enucleation of intramural uterine fibroids in women at fertile age: midterm results of prospective clinical trials. Ces Gynek 71:16-24

28. Milad MP, Morrison K, Sokol A, Miller D, Kirkpatrick L (2001) A comparison of laparoscopic supracervical hysterectomy vs laparoscopically assisted vaginal hysterectomy. Surg Endosc 15: 286-288

29. Obed JY, Bako B, Usman J, Moruppa JY, Kadas S (2011) Uterine fibroids: risk of recurrence after myomectomy in a Nigerian population. Arch Gynecol Obstet 283:311-315

30. Palomba S, Zupi E, Falbo A, Russo T, Marconi D, Zullo F (2010) New tool (Laparotenser) for gasless laparoscopic myomectomy: a multicenter-controlled study. Fertil Steril 94:1090-1096

31. Phillips DR, Nathanson HG, Milim SJ, Haselkorn JS (1995) 100 laparoscopic hysterectomies in private practice and visiting professorship programs. J Am Assoc Gynecol Laparosc 3(1):47-53

32. Pron G, Mocarski E, Cohen M, Colgan T, Bennett J, Common A (2003) Hysterectomy for complications after uterine artery embolization for leiomyoma: results of a Canadian multicenter clinical trial. J Am Assoc Gynecol Laparosc 10(1):99-106

33. Silva BAC, Falcone T, Bradley L, Goldberg J, Mascha E, Lindsey $\mathrm{R}$ et al (2000) Case-control study of laparoscopic versus abdominal myomectomy. J Laparoendosc Adv S 10(4):191-197

34. Sinha R, Hegde A, Mahajan C, Dubey N, Sundaram M (2008) Laparoscopic myomectomy: do size, number, and location of the myomas form limiting factors for lapaorsopic myomectomy? J Minim Invasive Gynecol 15:292-300

35. Tinelli A, Hurst BS, Hudelist G, Tsin DA, Stark M, Mettler L et al (2012) Laparoscopic myomectomy focusing on the myoma pseudocapsule: technical and outcome reports. Hum Reprod 27(2):427-435

36. Varma R, Soneja H, Clark T, Gupta J (2009) Hysteroscopic myomectomy for menorrhagia using Versascope bipolar system: efficacy and prognostic factors at a minimum of one year follow up. Eur J Obstet Gynecol Reprod Biol 142:154-159

37. Venkatesan AM, Partanen A, Pulanic T, Dreher MR, Fischer J, Zurawin RK et al (2012) Magnetic resonance imaging-guided volumetric ablation of symptomatic leiomyomata: correlation of imaging with histology. J Vasc Interv Radiol 23:786-794

38. Wamsteker K, Emanuel MH, de Kruif JH (1993) Transcervical hysteroscopic resection of submucous fibroids for abnormal uterine bleeding: results regarding the degree of intramural extension. Obstet Gynecol 82:736-740

39. Wang CJ, Soong YK, Lee CL (2007) Laparoscopic myomectomy for large intramural and submucous fibroids. Int J Gynecol Obstet 97(3):206-207

40. Widrich T, Bradley LD, Mitchinson AR, Collins RL (1996) Comparison of saline infusion sonography with office hysteroscopy for the evaluation of the endometrium. Am J Obstet Gynecol 174:1327-1334

41. Williams CD, Marshburn PB (1998) A prospective study of transvaginal hydrosonography in the evaluation of abnormal uterine bleeding. Am J Obstet Gynecol 179:292-298

42. Barbieri R, Dilena M, Chumas J, Rein MS, Friedman AJ (1993) Leuprolide acetate depot decreases the number of nucleolar organizer regions in uterine leiomyomata. Fertil Steril 60(3):569-570

43. De Falco M, Staibano S, Mascolo M, Mignona C, Improda L, Ciociola F et al (2009) Leiomyoma pseudocapsule after presurgical treatment with gonadotropin releasing hormone agonists: relationship between clinical features and immunohistochemical changes. Eur J Obstet Gynecol Reprod Biol 144:44-47

44. DiLieto A, De Falco M, Mansueto G, De Rosa G, Pollio F, Staibano S (2005) Preoperative administration of GnRH-a plus tibolone to premenopausal women with uterine fibroids: evaluation of the clinical response, the immunohistochemical expression of PDGF, bFGF and VEGF and the vascular pattern. Steroids 70: 95-102

45. Ferrari MM, Berlanda N, Mezzopane R, Ragusa G, Cavallao M, Pardi G (2000) Identifying the indications for laparoscopically assisted vaginal hysterectomy: a prospective, randomised comparison with abdominal hysterectomy in patients with symptomatic uterine fibroids. Br J Obstet Gynaecol 107:620-625

46. Levens ED, Wesley R, Prekumar A, Blocker W, Nieman LK (2009) Magnetic resonance imaging and transvaginal ultrasound for determining fibroid burden: implications for research and clinical care. Am J Obstet Gynecol 200:537e1-537.e7

47. Lim SS, Sockalingam JK, Tan PC (2008) Goserelin versus leuprolide before hysterectomy for uterine fibroids. Int $\mathrm{J}$ Gynecol Obstet 101:178-183

48. Litta P, Fantinato S, Calonaci F, Cosmi E, Filippeschi M, Zerbetto I et al (2010) A randomized controlled study comparing harmonic versus electrosurgery in laparoscopic myomectomy. Fertil Steril 94(5): $1882-1886$

49. Mais V, Ajossa S, Guerriero S, Mascia M, Solla E, Melis GB (1996) Laparoscopic versus abdominal myomectomy: a prospective, randomized trial to evaluate benefits in early outcome. Am J Obstet Gynecol 174:654-658

50. Marana R, Busacca M, Zupi E, Garcea N, Paparella P, Catalano GF (1999) Laparoscopically assisted vaginal hysterectomy versus total abdominal hysterectomy: a prospective, randomized, multicenter study. Am J Obstet Gynecol 180:270-275

51. Miskry T, Magos A (2003) Randomized, prospective, doubleblind comparison of abdominal and vaginal hysterectomy in women without uterovaginal prolapse. Acta Obstet Gynecol Scand 82:351-358

52. Palomba S, Orio F Jr, Russo T, Falbo A, Tolino A, Lombardi G et al (2005) Antiproliferative and proapoptotic effects of raloxifene on uterine leiomyomas in postmenopausal women. Fertil Steril 84:154-161

53. Palomba S, Orio F Jr, Russo T, Falbo A, Marconi D, Tolino A et al (2007) A multicenter randomized, controlled study comparing laparoscopic versus minilaparotomic myomectomy: short-term outcomes. Fertil Steril 88:942-951

54. Rein MS, Friedman AJ, Stuart JM, MacLaughlin DT (1990) Fibroid and myometrial steroid receptors in women treated with gonadotropin-releasing hormone agonist leuprolide acetate. Fertil Steril 53(6):1018-1023

55. Rutgers JL, Spong CY, Sinow R, Heiner J (1995) Leuprolide acetate treatment and myoma arterial Size. Obstet Gynecol 86: 386-388

56. Sayyah-Melli M, Tehrani-Gadim S, Dastranj-Tabrizi A, Gatrehsamani F, Morteza G, Ouladesahebmadarek E et al (2009) Comparison of the effect of gonadotropin-releasing hormone agonist and dopamine receptor agonist on uterine myoma 
growth. Histologic, sonographic, and intra-operative changes. Saudi Med J 30(8):1024-1033

57. Schutz K, Possover M, Merker A, Michels W, Schneider A (2002) Prospective randomized comparison of laparoscopic-assisted vaginal hysterectomy (LAVH) with abdominal hysterectomy (AH) for the treatment of the uterus weighing $>200 \mathrm{~g}$. Surg Endosc 16:121125

58. Seracchioli R, Venturoli S, Vianello F, Govoni F, Cantarelli M, Gualerzi B et al (2002) Total laparoscopic hysterectomy compared with abdominal hysterectomy in the presence of a large uterus. J Am Assoc Gynecol Laparosc 9(3):333-338

59. Shergill SK, Shergill HK, Gupta M, Kaur S (2002) Clinicopathological study of hysterectomies. J Indian Med Assoc 100(4):238-239

60. Tan J, Sun Y, Zhong B, Dai H, Wang D (2009) A randomized, controlled study comparing minilaparotomy versus isobaric gasless laparoscopic assisted minilaparotomy myomectomy for removal of large uterine myomas: short-term outcomes. Eur J Obstet Gynecol Reprod Biol 145:104-108

61. Tan J, Sun Y, Dai H, Zhong B, Wang D (2008) A randomized trial of laparoscopic versus laparoscopic-assisted minilaparotomy myomectomy for removal of large uterine myoma: short-term outcomes. J Minim Invasive Gynecol 15:402-409

62. Van Dongen H, Emanuel MH, Wolterbeek R, Trimbos JB, Jansen FW (2008) Hysteroscopic morcellator for removal of intrauterine polyps and myomas: a randomized controlled pilot study among residents in training. J Minim Invasive Gynecol 15:466-471

63. Williams A, Critchley H, Osei J, Ingamells S, Cameron IT, Han C et al (2007) The effects of the selective progesterone receptor modulator asoprisnil on the morphology of the uterine tissues after 3 months treatment in patients with symptomatic uterine leiomyomata. Hum Reprod 22(6):1696-1704

64. Yen YK, Liu WM, Yuan CC, Ng HT (2002) Comparison of two procedures for laparoscopic-assisted vaginal hysterectomy of large myomatous uteri. J Am Assoc Gynecol Laparosc 9(1):63-69

65. Ylikorkala O, Tiitinen A, Hulkko S, Kivinen S, Nummi S (1995) Decrease in symptoms, blood loss and uterine size with nafarelin acetate before abdominal hysterectomy: a placebo-controlled, double-blind study. Hum Reprod 10(6):1470-1474

66. Zhu L, Lang JH, Liu CY, SHI HH, Zun ZJ, Fan R (2009) Clinical assessment for three routes of hysterectomy. Chin Med J 122(4): 377-380

67. Zullo F, Palomba S, Corea D, Pellicano M, Russo T, Fablo A et al (2004) Bupivacaine plus epinephrine for laparoscopic myomectomy: a randomized placebo-controlled trial. Obstet Gynecol 104: 243-249

68. Adelusola KA, Ogunniyi SO (2001) Hysterectomies in Nigerians: histopathological analysis of cases seen in Ile-Ife. Niger Postgrad Med J 8(1):37-40

69. Angle HS, Cohen SM, Hidlebaugh D (1995) The initial Worcester experience with laparoscopic hysterectomy. J Am Assoc Gynecol Laparosc 2(2):155-161

70. Banaczek Z, Sikora K, Lewandowska-Andruszuk I (2004) The occurrence of leiomyoma cellulare in the surgical material in the department of obstetrics and gynecology in the district specialized hospital in Radom. Ginekol Pol 75(11):858-862

71. Betjes HE, Hanstede M, Emanuel M, Stewart EA (2009) Hysteroscopic myomectomy and case volume hysteroscopic myomectomy performed by high- and low-volume surgeons. J Reprod Med 54:425-428

72. Bushaqer NJ, Dayoub N (2014) The effect of uterine leiomyomas size on presenting symptoms and accurate sonography assessment. Bahrain Med Bull 36(2):74-77

73. Butt JL, Jeffery ST, Van der Spuy ZM (2012) An audit of indications and complications associated with elective hysterectomy at a public service hospital in South Africa. Int J Gynecol Obstet 116: $112-116$

74. Colgan TJ, Pendergast S, LeBlanc M (1993) The histopathology of uterine leiomyomas following treatment with gonadotropinreleasing hormone analogues. Hum Pathol 24(10):1073-1077

75. Corson SL, Brooks PG (1991) Resectoscopic myomectomy. Fertil Steril 55:1041-1044

76. Deligdisch L, Hirschmann S, Altchek A (1997) Pathologic changes in gonadotropin releasing hormone agonist analogue treated uterine leiomyomata. Fertil Steril 67:837-841

77. Dundr P, Mara M, Maskova J, Fucikova Z, Povysil C, Tvrdik D (2006) Pathological findings of uterine leiomyomas and adenomyosis following uterine artery embolization. Pathol Res Pract 202:721-729

78. El-Mowafi D, Madkour FW, Facharzt, Lall CL, Wenger JM (2004) Laparoscopic supracervical hysterectomy versus laparoscopic-assisted vaginal hysterectomy. J Am Assoc Gynecol Laparosc 11(2):175-180

79. Emanuel MH, Wamsteker K, Hart A, Metz G, Lammes FB (1999) Long-term results of hysteroscopic myomectomy for abnormal uterine bleeding. Obstet Gynecol 93:743-748

80. Emanuel M, Wamsteker K (2005) The intra uterine morcellator: a new hysteroscopic operating technique to remove intrauterine polyps and myomas. J Minim Invasive Gynecol 12:62-66

81. Fukuda M, Shimizu T, Fukuda K, Yomura W, Shimizu S (1993) Transvaginal hysterosonography for differential diagnosis between submucous and intramural myoma. Gynecol Obstet Investig 35:236-239

82. Gavai M, Hupuczi P, Papp Z (2006) Abdominalis myomectomia, mint a hysterectomia alternativaja: 504 eset analizise. Orv Hetil 147:971-8

83. Gaym A (2004) Leiomyoma uteri in Ethiopian women: a clinical study. Ethiop Med J 42:199-204

84. Goldrath MH (1990) Vaginal removal of the pedunculated submucous myoma. Am J Reprod Med 35(10):921-924

85. Gowri M, Mala G, Murthy S, Nayak V (2013) Clinicopathological study of uterine leiomyomas in hysterectomy specimens. J Evol Med Dent Sci 46(2):9002-9009

86. Grigoriadis C, Papaconstantinou E, Mellou A, Hassiakos D, Liapis A, Kondi-Pafiti A (2012) Clinicopathological changes of the uterine leiomyomas after GnRH agonist therapy. Clin Exp Obstet Gynecol 39(2):191-194

87. Gurung G, Pradhan N, Rawal S, Rana A, Ghimire S, Baral J (2009) Myomectomy: TU teaching hospital experiences. NJOG 4(1):15-18

88. Hallez J (1995) Single-stage total hysteroscopic myomectomies: indications, techniques, and results. Fertil Steril 63(4):703-708

89. Hanafi M (2005) Predictors of leiomyoma recurrence after myomectomy. Obstet Gynecol 105:877-881

90. Hanafi M (2013) Ultrasound diagnosis of adenomyosis, leiomyoma, or combined with histopathological correlation. J Hum Reprod Sci 6(3):189-193

91. Harmanli OH, Bevilacqua SA, Dandolu V, Chatwani AJ, Hernandez E (2005) Adenomyosis interferes with accurate ultrasonographic detection of uterine leiomyomas. Arch Gynecol Obstet 273:146-149

92. Hasson HM, Rotman C, Rana N, Sistos F, Dmowski WP (1992) Laparoscopic myomectomy. Obstet Gynecol 80(5):884-888

93. Hasson HM, Rotman C, Rana N, Asakura H (1993) Experience with laparoscopic hysterectomy. J Am Assoc Gynecol Laparosc $1(1): 1-11$

94. Huang JQ, Lathi RB, Lemyre M, Rodriguez HE, Nezhat $\mathrm{CH}$, Nezhat C (2010) Coexistence of endometriosis in women with symptomatic leiomyomas. Fertil Steril 94:720-723

95. Jha R, Pant AD, Jha A, Sayami G (2006) Histopathological analysis of hysterectomy specimens. J Nep Med Assoc 45:283-290 
96. Johns D, Diamond MP (1994) Laparoscopically assisted vaginal hysterectomy. J Reprod Med 39:424-428

97. Kafy S, Huang JYJ, Al-Sunaidi M, Wiener D, Tulandi T (2006) Audit of morbidity and mortality rates of 1792 hysterectomies. J Minim Invasive Gynecol 13:55-59

98. Kamikabeya TS, Etchebehere RM, Nomelini RS, Murta EF (2010) Gynecological malignant neoplasias diagnosed after hysterectomy performed for leiomyoma in a university hospital. Eur J Gynaecol Oncol 31(6):651-653

99. Klimentova DV, Braila AD, Simionescu C, Ilie I, Braila MB (2012) Clinical and paraclinical study regarding the macro- and microscopic diagnosis of various anatomo-clinical forms of operated uterine fibromyoma. Romanian J Morphol Embryol 53(2): 369-373

100. Leibsohn S, d'Ablaing G, Mishell DR, Schlaerth JB (1990) Leiomyosarcoma in a series of hysterectomies performed for presumed uterine leiomyomas. Am J Obstet Gynecol 162:968-976

101. Leung F, Terzibachian J, Gay C, Chung Fat B, Aouar Z, Lassabe C et al (2009) Hysterectomies performed for presumed leiomyomas: should the fear of leiomyosarcoma make us apprehend non laparotomic surgical routes? Gynecol Obstet Fertil 37:109-114

102. Lyons TL, Adolph AJ, Winer WK (2004) Laparoscopic supracervical hysterectomy for the larger uterus. J Am Assoc Gynecol Laparosc 11(2):170-174

103. MacKenzie IZ, Naish C, Rees M, Manek S (2004) 1170 consecutive hysterectomies: indications and pathology. J Br Menopause Soc 10(3):108-112

104. Mansour FW, Kives S, Urbach DR, Lefebvre G (2012) Robotically assisted laparoscopic myomectomy: a Canadian experience. J Obstet Gynaecol Can 34(4):353-358

105. Mecke H, Wallas F, Brocker A, Gertz HP (1995) Pelviskopische myomenukleation: technik, grenzen, komplikationen. Geburtsh Franuenheilk 55:374-379

106. Mettler L, Alvarez-Rodas E, Semm K (1995) Hormonal treatment and pelviscopic myomectomy. Diagn Ther Endosc 1:217-221

107. Moghadam R, Lathi RB, Shahmohamady B, Saberi NS, Nexhat $\mathrm{CH}$, Nezhat $\mathrm{F}$ et al (2006) Predictive value of magnetic resonance imaging in differentiating between leiomyoma and adenomyosis. JSLS 10:216-219

108. Muhammad Z, Ibrahaim SA, Agu OC (2009) Total abdominal hysterectomy for benign gynaecological tumours in Jos University teaching hospital, Jos Plateau State. BoMJ 6(2):2-19

109. Munoz JL, Jimenez JS, Hernandez C, Vaquero G, Sagaseta P, Noguero R et al (2003) Hysteroscopic myomectomy: our experience and review. JSLS 7:39-48

110. Nezhat F, Nezhat CH, Admon D, Gordon S, Nezhat C (1995) Complications and results of 361 hysterectomies performed at laparoscopy. J Am Coll Surg 180:307-316

111. O'Hanlan KA, Dibble SL, Garnier A, Reuland ML (2007) Total laparoscopic hysterectomy: technique and complications of 830 cases. JSLS 11(1):45-53

112. Okezie O, Ezegwui HU (2006) Management of uterine fibroids in Enugu. Niger J Obstet Gynaecol 26(4):363-365

113. Ouldamer L, Rossard L, Arbion F, Marret H, Body G (2014) Risk of incidental finding of endometrial cancer at the time of hysterectomy for benign condition. J Minim Invasive Gynecol 21:131145

114. Parker WH, Fu YS, Berek JS (1994) Uterine sarcoma in patients operated on for presumed leiomyoma and rapidly growing leiomyoma. Obstet Gynecol 83:414-418

115. Paul GP, Sejal A, Madhu KN, Thomas T (2010) Complications of laparoscopic myomectomy: a single surgeon's series of 1001 cases. Aust N Z J Obstet Gynaecol 50:385-390

116. Perveen S, Tayyab S (2008) A clinicopathological review of elective abdominal hysterectomy. JSP 13(1):26-29
117. Polena V, Mergui J, Perrot N, Poncelet C, Barranger E, Uzan S (2007) Long-term results of hysteroscopic myomectomy in 235 patients. Eur J Obstet Gynecol Reprod Biol 130:232-237

118. Radosa MP, Owsianowski Z, Mothes A, Weisheit J, Vorwergk J, Asskaryar FA et al (2014) Long-term risk of fibroid recurrence after laparoscopic myomectomy. Eur J Obstet Gynecol Reprod Biol 2-14(180):35-39

119. Reiter RC, Wagner PL, Gambone JC (1992) Routine hysterectomy for large asymptomatic uterine leiomyomata: a reappraisal. Obstet Gynecol 79(4):481-484

120. Rosenblatt P, Makai G, DiSciullo A (2010) Laparoscopic supracervical hysterectomy with transcervical morcellation: initial experience. J Minim Invasive Gynecol 17:331-336

121. Rovio PH, Helin R, Heinonen PK (2009) Long-term outcome of hysteroscopic endometrial resection with or without myomectomy in patients with menorrhagia. Gynecol Obstet 279:159-163

122. Sahagun Quevedo JA, Perez Ruiz JC, Cherem B, Efren PG (1994) Analysis of 1,000 hysterectomies. Technical simplifications and reflections. Ginecol Obstet Mex 62:35-39

123. Samaila M, Adesiyun AG, Agunbiade OS, Mohammed-Duro A (2009) Clinico-pathological assessment of hysterectomies in Zaria. Eur J Gen Med 6(3):150-153

124. Seidman MA, Oduyebo T, Muto MG, Crum CP, Nucci MR, Quade BJ (2012) Peritoneal dissemination complicating morcellation of uterine mesenchymal neoplasms. PLoS ONE 7(11):1-8

125. Seki K, Hoshihara T, Nagata I (1992) Leiomyosarcoma of the uterus: ultrasonography and serum lactate dehydrogenase level. Gynecol Obstet Investig 33:114-118

126. Shen C, Wu M, Kung F, Huang FJ, Hsieh CH, Lan KC et al (2003) Major complications associated with laparoscopic-assisted vaginal hysterectomy: ten-year experience. J Am Assoc Gynecol Laparosc 10(2):147-153

127. Sikora-Szczesniak DL, Sikora W, Szczesniak G (2013) Leimyoma cellular in postoperative material: clinical cases. Studia Medyczne 29(2):144-151

128. Takamizawa S, Minakami H, Usui R, Noguchi S, Ohwada M, Suzuki M et al (1999) Risk of complications and uterine malignancies in women undergoing hysterectomy for presumed benign leiomyomas. Gynecol Obstet Investig 48:193-196

129. Theben JU, Schellong A, Altgassen C, Kelling K, Schneider S, Grobe-Drieling D (2013) Unexpected malignancies after laparoscopic-assisted supracervical hysterectiomes (LASH): an analysis of 1,584 cases. Arch Gynecol Obstet 287:455-462

130. Uccella S, Cromi A, Serati M, Casarin J, Sturla D, Ghezzi F (2014) Laparoscopic hysterectomy in case of uteri weighing $>1$ kilogram: a series of 71 cases and review of the literature. J Minim Invasive Gynecol 21:460-465

131. Ueki M, Okamoto Y, Tsurunaga T, Seiki Y, Ueda M, Sugimoto O (1995) Endocrinological and histological changes after treatment of uterine leiomyomas with danazol or buserelin. J Obstet Gynaecol 21(1):1-7

132. Walid MS, Heaton RL (2010) Laparoscopic myomectomy: an intent-to-treat study. Arch Gynecol Obstet 281:645-649

133. West S, Ruiz R, Parker WH (2006) Abdominal myomectomy in women with very large uterine size. Fertil Steril 85:36-39

134. Wortman M, Daggert A (1995) Hysteroscopic myomectomy. J Am Assoc Gynecol Laparosc 3(1):39-46

135. Yoo EH, Lee PI, Huh CY, Kim DH, Lee BS, Lee JK et al (2007) Predictors of leiomyoma recurrence after laparoscopic myomectomy. J Minim Invasive Gynecol 14:690-697

136. Yoon HJ, Kyung MS, Jung US, Choi JS (2007) Laparoscopic myomectomy for large myomas. J Korean Med Sci 22:706-712

137. Harbour R, Miller J (2001) A new system for grading recommendations in evidence based guidelines. BMJ 323:334-336 
138. Bradburn MJ, Deeks JJ, Berlin JA, Russell Localio A (2007) Much ado about nothing: a comparison of the performance of meta-analytical methods with rare events. Stat Med 26:53-77

139. Altman DG, Deeks JJ (2002) Meta-analysis, Simpson's paradox, and the number needed to treat. BMC Med Res Methodol 2:3

140. Kulinskaya E, Morgenthaler S, Staudte RG (2008) Meta Analysis: a guide to calibrating and combining statistical evidence, Chapter 2. Wiley, Chichester

141. Higgins J, Thompson SG, Spiegelhalter DJ (2009) A re-evaluation of random effects meta-analysis. J R Stat Soc Ser A Stat Soc 172: $137-159$
142. Sutton AJ, Cooper NJ, Lambert PC, Jones DR, Abrams KR, Sweeting MJ (2002) Meta-analysis of rare and adverse event data. Expert Rev Pharmacoecon Outcomes Res 2:367-379

143. Menon GR, Sundram KR, Pandey RM, Prasad K, Handa BR, Singh P (2006) Application of hierarchical Bayesian linear model in meta-analysis. Int J Stat Sci 5:85-108

144. Rowland M, Lesnock J, Edwards R et al (2012) Occult uterine cancer in patients undergoing laparoscopic hysterectomy with morcellation. Gynecol Oncol S29

145. Leung F, Terzibackian JJ (2012) Re "The impact of morcellation during surgery on the prognosis of patients with apparently early uterine leiomyosacroma”. Gynecol Oncol 124(1):172-173 